\title{
A RE-IDENTIFICAÇÃO DE REFERENCIAIS PARA A INTERVENÇÃO DO ENFERMEIRO NO ÂMBITO DE SAÚDE DO ADULTO
}

Cilene Aparecida Costardi Ide *

IDE, C.A.C. A re-identificaça de referenciais para a intervençăo do enfermeiro no ambito de saúde do adulto. Rev.Esc.Enf.USP, Número Especial, p. 9-32, dez. 1996.

Este arigo tem como foco a proposição de um novo modelo de formação no âmbito da graduação em enfermagem. Nesse contexto, foram configurados os códigos moduladores da ação pedagógica, bem como os sistemas referenciais que lhes dão sustencão.

UNITERMOS: Processo ensino-aprendizagem. Processo de cuidar.

A iniciativa de investir no processo de reinterpretação da atuação e da formação do enfermeiro, tentando reconsiderar os referenciais, tentando tomar o partido da realidade visível contra idealizações da prática, tem configurado uma experiência desafiadora, compartilhada por mim e por CHAVES no decorrer da nossa atividade docente.

Preliminarmente, retomamos o processo de institucionalização das práticas de saúde enquanto marco da ruptura de um modelo vinculado ao senso comum e, conseqüentemente, marco para a conformação da trajetória da Enfermagem enquanto atuação profissional.

Nesse sentido, como primeira referência para a nossa proposição considerávamos que na esfera do processo de trabalho, a institucionalização das práticas de saúde ${ }^{9}$ insere o médico nesse cenário, conferindo-lhe o poder e o dever de curar. Como sustentação para a sua atuação, a Enfermagem profissional também é institucionalizada, tendo como atribuiç̃o peculiar promover condicões para o êxito da relação terapêutica-médico-doente. Sua intervenção passa a ter como especificidade não a relaç̃o dual - profissional - doente - comum à prática médica e sim uma atuação voltada ao controle do ambiente, considerando condições de higiene, iluminação, aeração; ao controle das pessoas nele inseridas, estabelecendo uma relação dúbia manifesta pela adesão ao poder médico investido de poder administrativo e de coerção para com trabalhadores e doentes; ao controle do tempo e dos movimentos, determinando locais, horários e ritmos de trabalho

* Professora Livre Docente do Departamento de Enfermagem Médico-Cirúrgica da USP.

Rev.Esc.Enf.USP, v.30, n. Especial, p.9-32, dez. 1996. 
pertinentes ao modelo e também, ao controle do processo de formação, estabelecendo pressupostos norteadores da conduta moral e da atuação profissional do escalão responsável, tanto pela mediação das ações dos profissionais de nível superior quanto pelos responsáveis pelo cuidado direto, incluindo profissionais advindos de outros níveis e padrões de formação.

Nesse contexto, a sociedade do século 19 institucionaliza a Enfermagem, agora, como profissão responsável pelo ambiente hospitalar em sua nova versão, ou seja, a recuperação de vidas necessárias à sustentação do sistema. Essa inserção, se por um lado organiza o cenário, por outro reitera o que de mais cristalizado o hospital tem, ou seja, o seu caráter total, que a todos limita e adequa a papéis sociais enquanto "construções socialmente determinadas, constituindo sistemas que permitem aos membros de uma sociedade mecanizar a maior parte de suas ações pela imitação ativa da totalidade dos comportamentos valorizados"3. Énesse contexto que emergem conflitos ainda presentes na prática do enfermeiro. A sociedade se apropriou de demandas psíquicas dos que cuidavam para responder, tanto a demandas sociais (manter a forca de trabalho) quanto a expectativas institucionais (controle e gestão do processo de trabalho no âmbito da saúde), amortecendo a demanda por cuidar através de funções que contemplam porém não dominam o cuidar enquanto prerrogativa da atuação do enfermeiro.

Sua intervenção passa a ter por especificidade delegada a mediação das relações de poder: o controle do contexto, agregando ambiente e infra estrutura de funcionamento, e a sustentação da prática assistencial multiprofissional $e$ que, no âmbito intrínseco, pressupõe o controle da própria equipe de auxiliares, por ela formada e por ela utilizada para a prestação dos cuidados.

Frente a essa realidade, analisar a prática dos enfermeiros no âmbito da Enfermagem pressupõe: reconhecer a abrangência dessa atuação; superar a falsa conotação de inespecificidade decorrente da delegação do cuidar e, primordialmente, desenvolver a dimensão que mais lhe confere identidade $e$ que, paradoxalmente ainda se mantém oculta, ou seja, a esfera das relações e dos poderes subjacentes, enquanto elementos a serem considerados, tanto no âmbito da formação quanto no da utilização de recursos humanos. ${ }^{9}$

Dessa convicção emergia para nós uma segunda referência, ou seja: propor mudanças nesse contexto pressupunha atuar no substrato afetivo-simbólico dos enfermeiros uma vez que conscientemente, cognitivamente, já havia um consenso cientificamente fundamentado quanto d̀ nossa origem e à nossa razão de ser dentro do hospital. A resistência só poderia decorrer de outras características pessoais, nesse caso, compartilhadas pela maioria do grupo profissional.

Nesse contexto, a Sociologia já não bastava para fundamentar nossa iniciativa. Buscamos, agora, o referencial da Psicologia Social na tentativa de compreensão, tanto da natureza das barreiras como também das perspectivas de proposição. E nela identificamos um significativo contingente de trabalhos que tinham como questão teórica central a interação profissional - profissão 
Enfermagem. A característica central dessas pesquisas relacionava-se à confirmação de um padrão peculiar de resposta pessoal ao contexto profissional, pautado: na necessidade compulsiva de ter uma realidade transcendente sob controle; por desdobramento, na adesão aos mecanismos de controle social instituídos e instituintes da dinâmica hospitalar; uma perpetuação de relações interpessoais esvaziadas de identidade por uma dinâmica de atuação fragmentada, repetitiva, apta a justificar a delegação de responsabilidade e a postergação de tomadas de decisão, inviabilizando e desfigurando cada vez mais o controle pretendido. ${ }^{13,16}$

Assim, ambas considerávamos que mesmo quando, em tese, a meta central de uma interação ${ }^{9}$ seja o atendimento ao doente, sob a ótica dos papeis sociais, os objetivos dos sujeitos nem sempre são completamente coincidentes. É possível afirmar, inclusive, que o processo de hospitalização constitui uma vivência de significados diferentes, em alguns aspectos, inclusive, opostos para os sujeitos que dele participam. Essas diferenças de significados possibilitam o surgimento de concepções e atitudes distintas diante da mesma situação, o que poderá implicar em equívocos de julgamento em relação ao outro, gerando impossibilidade de empatia, insatisfações, inseguranças, isolamento e até mesmo tendências paranóides. $^{9}$

Centrando ${ }^{9}$ nossa análise unicamente no "papel do paciente" e no "papel do enfermeiro" temos que para o primeiro a ho:pitalização constitui-se num momento peculiar de descontinuidade no trajeto dos diferentes papéis que desempenha na vida e dos projetos que estabeleceu para si. É um estado de ruptura com a essência singular do sujeito, onde a imposição e a coerção estão presentes desde a opção pela internação, até o momento da alta.

No que se refere ao enfermeiro, o significado da hospitalização é exatamente oposto, isto é, não há ruptura e sim continuidade do seu projeto de vida profissional. Não altera os papéis sociais que desempenha, ao contrário, os reforca na medida em que afirma sua identidade profissional e seus desdobramentos.

Para o paciente a internação freqüentemente é vista e sentida como algo transitório; um mal necessário que permitirá seu retorno a um estado de saúde compatível com sua vida cotidiana. Na busca desse objetivo submete-se a sofrimentos de diversas naturezas, e para suportá-los lanca mão de mecanismos de defesa característicos de pessoas ameacadas mas ao mesmo tempo subjulgadas e impotentes diante do agente ameacador.

Para a enfermeira, o processo de internação pode ser sentido como um momento de ameaca ao seu cotidiano já conhecido e, de certa forma, controlado. A cada nova internação a enfermeira se vê diante de novas demandas trazidas pelas características da personalidade do doente, dos familiares e pela exigência técnica da própria doença as quais, muitas vezes, não se sente apta a atender. Diante dessa situação, a enfermeira também utilizará mecanismos de defesa os quais, no entanto, serão distintos daqueles utilizados pelos pacientes pois, embora 
em ambos os casos os sujeitos percebam o perigo, no caso específico da enfermeira ela identifica possibilidades de neutralizá-lo.

Surge, portanto, mais um objetivo a ser alcançado no decorrer da hospitalização, ou seja: mobilizar recursos internos para enfrentar as ameaças identificadas. Este segundo objetivo, a princípio, não caracteriza um obstáculo para a consecução do primeiro, no entanto, pode dificultá-lo consideravelmente na medida em que o substrato psíquico dos sujeitos envolvidos não constitui um suporte eficaz para a avaliação e para o enfrentamento de situações ameacadoras. Nesse caso, o sujeito pode inverter as prioridades dos objetivos e agir, mesmo que inconscientemente, muito mais no sentido de neutralizar os riscos identificados $e$ diminuir sua própria ansiedade do que atender às reais necessidades do doente. ${ }^{g}$

Ao mesmo tempo considerada como elemento e como produto desse contexto, a atuação do enfermeiro passa a configurar um intenso e constante processo de sofrimento psíquico. Segundo BORSOI ${ }^{2}$, um dos principais motivos para esse sofrimento seria o sentimento persecutório gerado pela imprevisibilidade das conseqüências do seu trabalho, para si e para o doente em virtude de estarem $a$ mercê da administração do hospital; pela impossibilidade de assegurar a recuperação do paciente e pela subordinação do seu trabalho ao poder médico. $O$ comportamento defensivo diante disto manifesta-se pelo uso demasiado da vigilância dirigida aos fatos, aos sujeitos e às coisas que compõem seu cotidiano de trabalho, com o objetivo de evitar a perda de controle, a culpa e a punição. Diante deste cenário, situações novas podem significar ameaças, na medida em que envolve sujeitos e fatos desconhecidos a principio, e portanto fora de controle. ${ }^{2}$

Frente a um ser em defensiva, qualquer iniciativa de modelo alternativo de prática deveria, ao mesmo tempo, considerar demandas atávicas com força de perpetuação e propor mudanças passíveis de serem reconhecidas como pertinentes, porém não ameaçadoras a uma vivência que, apesar do sofrimento e da ineficiência propalada vem sendo intransigentemente mantida. Deveria, enfim, consolidarse a partir do núcleo de significações reconhecidas como essenciais para esse grupo profissional.

Uma terceira referência para a proposição de um novo padrão de capacitação profissional relaciona-se agora, à especificidade do processo pedagógico no âmbito da graduação. Processo analisado numa dupla perspectiva, considerando aspectos similares à esfera genérica do ensino superior e outros espećfficos à ação pedagogica em Enfermagem.

Preliminarmente, reconhecíamos a carência de pesquisas voltadas a formação de nível superior. MASETTO ${ }^{12}$ afirma em sua tese de livre docência:

Analisando as condicôes apontadas como facilitadoras de aprendizagem nas diversas pesquisas, encontrei um traco comum que perpassava por todas elas: o aluno tratado como adulto, com experiências e conhecimentos próprios $e$ co-responsável pelo seu processo de aprendizagem. Dei-me conta de que esta consideração do aluno universitário como adulto não é tão comum entre nós 
professores. Talvez a idade deles nos leve a enxergá-los como jovens, e, por vezes, inexperientes; talvez o fato de nem todos ainda exercerem uma profissão qualificada; talvez seu ar jocoso e juvenil... o certo é que apenas aqueles com idade mais avançada e ocupação profissional mais definida são considerados por nós como adultos. Mas, o nosso modo de tratar o grupo e nos relacionar com o grupo se assemelha muito mais a um professor de $2^{\circ}$. grau.

Com efeito, nós trazemos para cima de nossos ombros a responsabilidade total ou maior pela aprendizagem dos alunos. Nós planejamos o curso, nós damos as aulas, preparamos as apostilas, corrigimos os trabalhos e exercícios, orientamos, guiamos, dirigimos, avaliamos, damos nota, aprovamos, reprovamos. O nosso aluno ouve, lê, estuda, anota, faz os exercícios e as provas, assiste às aulas. É pouco ativo, pouco participante, quase nada responsável nem responsabilizado por sua aprendizagem.

As pesquisas, porém, ao identificarem condições facilitadoras de aprendizagem apontam para a existência de comportamentos de responsabilidade pelo processo de aprendizagem, de participaç̃o ativa, de contribuição, de questionamentos, e de um conjunto de outras atitudes próprias de uma pessoa adulta.

Levantei então a hipótese de que subjacente a estas condições facilitadoras de aprendizagem estivessem presentes principios de aprendizagem de uma pessoa adulta.

Busquei nas teorias de aprendizagem quais seriam estes princípios e encontrei apenas orientações para a educação de adultos analfabetos, desejosos ou interessados na alfabetização, de adultos em cursos supletivos ou em cursos noturnos de 2o. grau. Começam aparecer estudos voltados para o desenvolvimento das atividades intelectuais ou de reciclagem para adultos já formados ou graduados e para adultos na 3a. idade. Mas, voltados para os alunos universitários considerados como alunos não encontrei trabalhos realizados.

Pesquisas feitas em universidades norte-americanas sobre a aprendizagem de adultos, compreensão do processo, arte de ensinar também entendem este adulto sob várias categorias, como por exemplo, o adulto já graduado participando de atividades de reciclagem, o adulto líder ou membro de comunidade, o adulto na $3 a$. idade e também, em alguns casos, o adulto nos cursos universitários ${ }^{2}$.

Estaria ocorrendo, portanto, o desenvolvimento de uma ação pedagógica pautada na replicação de experiências desenvolvidas junto a outros grupos de estudantes, em outras faixas etárias ou em outras condições de inserção no sistema formador. Pautada, inclusive, na repliçação não de modelos de ensino e sim de modelos de atuação profissional, reconhecidos como necessários e suficientes para o êxito da relação pedagógica.

Na Enfermagem, a especificidade do trabalho pedagogico desenvolvido em diferentes cursos de Graduação vem configurando pesquisas relevantes e que analisam, sob diferentes prismas, a realidade dessa atuação. 
Para MARTINS"1, "essa intervenção vem se pautando na vinculação entre ensino, pesquisa e extensão, configurando um conjunto que, pela complexidade $e$ abrangência, traz a marca de sua impossibilidade plena, da sua maturidade em consolidação. Sob as condições de existência dadas, ainda que pouco transparentes em todos os seus pontos, as instituições vêm tentando combinar possibilidades, reunir aquilo que permanece isolado, reconsiderar ações, na intenção de conduzir a prática acadêmica em consonância com padrões de atuação requintados. A figura docente compativel com essas expectativas seria a do pesquisador atuante, criativo, produtivo em quantidade e em qualidade, que teria no ensino o cenário para a validação e a continuidade de suas investigações, incluindo a captação de jovens talentos. Pesquisador apto a atuar em equipe, a aprofundar vínculos intra $e$ inter institucionais, a angariar recursos necessários à manutenção de suas pesquisas, incluindo a divulgação em eventos e em publicações. Esse desejo de competência, essa unidade de ação dão forma a um mundo exclusivo, onde questões relativas à viabilidade e às conseqüências desse nivel de exigência na vida desses docentes são aspectos pouco considerados. Nesse sentido, o caráter problemático dessa questão - transformar em real o que era um convite à idealização - passa a ser uma necessidade".

Nesse contexto, a amplitude de possibilidades de ação, a responsabilidade proporcional ao domínio de um universo em constante transformação, a possibilidade de acesso e de participação em um contexto acadêmico de porte internacional, a multiplicidade de interações, extrapolam os limites convencionais do trabalho, podendo promover diferentes formas de desgaste.

Desgaste físico, na medida em que o estresse e a atividade sedentária dentre outros fatores, seriam condicões suficientes para desencadear processos mórbidos. Desgaste psíquico, decorrente de uma necessidade de estar à frente, de responder ao inédito, de existir num contexto privilegiado às custas, inclusive, da competição, do isolamento e da ansiedade constante. Desgaste social na medida em que tal atividade, apesar de ainda valorizada, não encontra mais o respaldo econômico primordial à plena dedicacão. ${ }^{1}$

Trabalho docente que, segundo RIBEIRO ${ }^{15}$, configura rituais de ação peculiares, respaldadas por uma interação professor-aluno com um cunho de cumplicidade necessária ao abafamento de tensões decorrentes, primordialmente, do despreparo para compreender e enfrentar uma realidade assistencial e pedagógica transcendentes. Tendo o processo de ensino desenvolvido numa cultura institucional peculiar como pauta, a autora destaca os seguintes aspectos relativos à vivência docente: "o convívio com incertezas, decorrentes da impossibilidade de refletir/planejar o vir a ser no futuro; a vivência concomitante de duplo papel, representado pelo ser enfermeira e ser professora; o compromisso para com o cumprimento de todas as atividades que lhe são colocadas - o dar conta de tudo ; a prática do controle sobre as próprias ações e sobre as ações das alunas e a atuação por meio de rituais, que refletem a busca de certezas, de amenização de ansiedades e a não-disposição de correr riscos... Para tanto, a professora reitera 
o vigente, utilizando como estratégias o dizer o que fazer; o dizer como fazer e o dizer o que saber". ${ }^{15}$

Os dados obtidos por essa autora, diretamente relacionados à prática docente em Enfermagem Pediátrica, vêm revestidos de um caráter de generalização caracterizado sob dois aspectos. O primeiro, decorrente da ausência do ensinar a cuidar da crianca, especificidade pouco reconhecida pelos sujeitos dessa prática provavelmente porque, a adesão às rotinas assistenciais transcenda à peculiaridade do interagir com a criança e o seu contexto, enquanto objeto de uma ação desprovida de identidade. O segundo aspecto relativo à supremacia da dinâmica assistencial sobre a docência. Mais uma vez, a realidade do campo passa a ser a maior ou a mais reconhecida demanda a ser atendida pelo professor. Ao aluno, objeto de um processo de ensino em descompasso, caberia sobreviver a essa experiência da maneira menos iatrogênica possível, por sintonia ao vigente, tentando adequar-se às múltiplas, intensas, complexas e desconhecidas fontes de tensão e de ação. Pelo descompasso entre expectativas e possibilidades de respostas, pelo despreparo, pela pouca elaboração e, em decorrência, pela fragilidade dos mecanismos de defesa psíquica acionados em resposta a essa vivência, reitera-se a matriz de percepções, de representações e de atuações vinculadas ao senso comum, apesar da graduacão.

Assim sendo, ter o trabalho pedagógico como questão teórica pressupõe apreender finalidades, já revestidas de um sentido e de uma função peculiares ao modo de existência dessa prática. Trata-se, portanto, de reconhecer o próprio projeto de ser e de agir. Na Enfermagem, nossa maneira de existir em relação à dinâmica assistencial e acadêmica, pressupõe $\mathrm{e}^{8}$ :

- trabalhar com questões afetivas e simbólicas complexas. Na medida em que a sociedade transfere para a saúde a intermediacão do viver, adoecer e morrer ela determina a esses profissionais que convivam intensa e constantemente com a dor, o medo, com situações consideradas repugnantes., com a quebra dos limites do privado; com intervençoes invasivas, tanto na esfera física quanto na psíquica; com uma relação interpessoal intensa e desgastante (por isso negada) ; com a manipulação de hábitos, crenças e valores atemporais, calcados no inconsciente coletivo; com a necessidade de responder diferentes e conflitantes demandas que, quase sempre, extrapolam suas possibilidades enquanto pessoa e profissional;

- trabalhar com o poder e com papéis sociais característicos de uma instituição total. Nela o uso de mecanismos de defesa psíquica, desde os mais primitivos, compartilham a esfera das relacões interpessoais ao lado das práticas coercitivas e de cooptação. Nesse contexto, cabe à Enfermagem especificamente: uma atuação híbrida, onde a submissão ao poder real convive com a intermediação de decisões e de controle sobre o tempo, o espaço, os direitos e os registros inerentes 
à dinâmica hospitalar; trabalhar com questões de imagem complexas, reflexo da intervenção sobre um corpo a ser cuidado apesar de tudo, enfrentando tabus; respaldar sua prática ora na ciência, ora no senso comum contemporâneo; interferir no saber-poder médico, sustentando um sistema às custas da diluição da sua especificidade, aceitando $e$ se abatendo frente a uma falsa rejeição. Falsa inclusive porque não abolida e porque a fragilização dos seus agentes gera, como resposta, uma adesão mais visceral aos interesses dominantes. ${ }^{8}$

Falsa inespecificidade porque, na verdade, é dessa atuação no contexto, é dessa diversidade de ações que as demais profissões se utilizam e se aprimoram. Nesse interjogo de atuações, relações de poder se estabelecem e se desenvolvem, buscando esquemas de sustentação que têm na Enfermagem um mediador ainda pouco preparado para o enfrentamento e para o realinhamento, objetivado em novos hábitos de sentir, de pensar e de agir.

Assim o reconhecimento das condições determinantes, o re-situar o objeto da sua prática no contexto das demais, a sua reelaboração fundamentada no sentido de uma especificidade que transcenda a relação assistencial profissional - cliente comum às demais profissões de saúde, configuram alguns dos trajetos de uma profissão em movimento. Analisá-los de acordo com regras da razão e não de fé, aprofundar o poder de descoberta e de proposição, viabilizando o desenvolvimento da atuação e do conhecimento que lhe é peculiar, passa a ser o desafio para a Enfermagem.

Nesse processo de delimitação de um novo modo de existência profissional vale, agora, configurar o quarto aspecto a compor o seu quadro de referências, enquanto meio singular no qual diferentes noções se entrecruzam conformando o modelo em proposição.

Agora, o aspecto a merecer análise relaciona-se à dimensão a ser considerada como atributo da área Saúde do Adulto Institucionalizado. ${ }^{6}$ Nesse sentido, identificamos desdobramentos de competências, a fragmentacão desse Adulto diretamente relacionada à consolidação do saber-fazer assistência ao adulto. Tendo a ele - adulto como objeto, a Psiquiatria se apropria e se desenvolve a partir da dicotomia mente-corpo. A Obstetrícia identifica na mulher, na vigência do ciclo gravídico-puerperal, o seu núcleo de atuação, desconsiderando ou relativizando a vivência tanto pregressa quanto posterior a esse episódio na vida dessa mulher adulta. Em decorrência, talvez, da dicotomia prevenção-cura, da diversidade de programas de atendimento nesses dois âmbitos do assistir-cuidar, incluindo a diversidade do aparato institucional que sustenta ambas as intervençoes, temos uma especificidade consolidada em Doenças Transmissiveis que a isola das demais esferas de atendimento do Adulto. Mais recentemente, o adulto na sua condição de trabalhador vem constituindo outra especialidade pautada, agora, nas condições de trabalho e nas conseqüências dela advindas. E, permeando todas essas lógicas, temos todo um saber-fazer assistência do adulto 
na sua relação tanto com episódios mórbidos específicos - o adulto hipertenso, diabético, infartado, politraumatizado, dentre outras situações -, como também com padrões de atendimento peculiares. considerando a sua inserção no aparato hospitalar: UTI, Unidade de lnternação, Centro Cirúrgico, Ambulatório enquanto unidades com códigos moduladores de pertinência e com esquemas de enquadramento a gerar conseqüências na relação desse adulto com a sua doença e com o seu tratamento.

Nesse cenário, o nosso campo de atuação tomado em si é determinado enquanto contexto da assistência ao adulto institucionalizado excluindo-se $\alpha s$ mulheres no ciclo gravídico-puerperal as pessoas com distúrbios psiquiátricos e aquelas portadoras de doenças transmissiveis que apresentam as condições referidas como única manifestação. Essa é também a competência de intervenção reconhecida pelo Departamento de Enfermagem Médico-Cirúrgica da Escola de Enfermagem da USP, responsável pelo ensino, pesquisa e extensão desenvolvidas nesse âmbito de atuação.

Essa intervenção abrange conteúdos e práticas inerentes a um aparato institucional complexo, tecnológica e ideologicamente dominante, responsável pelo atendimento efetivado em unidades ambulatoriais de referência, em centros de reabilitação agregando, principalmente, unidades hospitalares de atendimento geral e especializado. É nesse aparato institucional que, por razões sóciohistoricamente determinadas, o maior contingente de pessoas com desvios em saúde reconhecidos como mórbidos - quando o acesso é conquistado - vêm sendo assistido. Nesse contexto, o modelo de institucionalização tem se justificado pela adesão a um perfil de mortalidade que tem nas doenças cardiovasculares, nas crônico-degenerativas e nas decorrentes de causas externas a sua maior expressão. A dimensão, a complexidade e a abrangência desse segmento da assistência, desenvolvida em instituições de nível secundário e terciário, implica na absorção do maior contingente de recursos humanos na saúde que demandam a.qualificação pretendida pela proposta que ora apresentamos. Cientes dos desvios inerentes a essa configuração, consideramos necessário tê-la como referência para a promoção de uma inserção profissional mais consciente nessa área.

Nesse cenário, que atribui significado e especificidade à Área, vale esclarecer que reconhecemos interfaces a serem conjuntamente consolidadas entre áreas afins. Reconhecemos ainda, a necessidade da interdisciplinaridade enquanto substrato para o aprofundamento das questões que têm na vivência do adulto $e$ na relação com o Sistema de Saúde o seu núcleo temático privilegiado. ${ }^{6}$

Frente a esses quatro referenciais nos propusemos, em conjunto, a esboçar um novo padrão de formação e de utilização de enfermeiros no âmbito da Saúde do Adulto Institucionalizado. Identificamos um clima que predispunha à adesão a um novo padrão de competência profissional uma vez que a fragilidade do vigente passava a ser gradativamente reconhecida. Instituições formadoras e utilizadoras de recursos humanos, docentes, alunos, diversas manifestações de usuários, a convivência conflitante e inquisidora com a realidade vêm conformando um 
substrato apto a possibilitar o indagar a respeito da racionalidade das proprias intervençōes. Sobre esse estado de inquietação, com a intensidade dos fatos que vem explicitando suas contradições, é possivel refletir e propor, no interesse pelo aprimoramento dessa atuação por nós considerada como imprescindível à sustentação das práticas em saúde. De fato, não fosse tendencial e crescentemente problemática a nossa intervenção, talvez não identificássemos nessa situação uma questão emergente. Nesse mundo tomado em si mesmo tudo é passivel de mudanças desde que admitamos os limites e, subjacente a eles, fragmentos de possibilidades a serem organizados e revestidos, agora, de outro sentido e função, conformando uma capacitação mais aderente à diversidade de demandas pela ação do enfermeiro.

\section{A proposição de um novo padrão funcional: o ensino e a prática do enfermeiro sob o prisma da coordenação do processo de cuidar do adulto institucionalizado.}

Uma iniciativa de reconsiderar a prática, enquanto processo a ser coletivamente constituído e validado no interior da dinâmica de trabalho em saúde pressupõe, preliminarmente a identificação dos pressupostos teóricos que a norteiam. Nesse sentido, cabe identificá-los numa seqüência que configura diferentes dimensões dessa realidade e que se encontram referidos a seguir:

. quanto à concepção acêrca de nossa dinâmica social cabe transcrever afirmações de ENZENSBERGER. ${ }^{14}$ Para esse autor, "temos uma nova forma da velha história da luta de classes que, com o crescimento e o desenvolvimento econômico, com a ampliação da classe média e o papel minguante da classe trabalhadora, muitos pensavam que desapareceria. Temos agora uma nova subclasse. Ela não é politicamente organizada, não tem partido, ideologia ou estandarte. Porém, está massivamente presente, ela existe, é forte, tem ligações em algumas partes do mundo, com o fundamentalismo, com o crime organizado, com minorias étnicas, etc. Sob diferentes formas, essa subclasse existe em toda parte e é naturalmente percebida como ameaça pelos que, em termos relativos, ainda são ganhadores. Temos, assim os elementos de uma nova guerra de classes, que não é mais política mas se desenvolve nas ruas". Situação aflitiva na medida em que se alia à um gradativo e crescente processo de destruição planetária, à uma inquietante modificação do padrão de morbimortalidade, acrescendo às doenças cardiovasculares, às crônico-degenerativas, e àquelas decorrentes de causas externas, a proliferação das doenças infecto-contagiosas reincidentes ou emergentes, com um poder de destruição ainda não apreendido em todas as nuances. E, primordialmente, a fragilização de todos os 
modelos convencionais de interpretar e de responder a esse contexto, incluindo o padrão de intervenção em Saúde e especificamente em Enfermagem, todos abalados em seus alicerces teórico-operacionais, configurando um processo anacrônico de reação.

. No Brasil, essa argumentação tem a consistência respaldada na realidade diária. Vivemos hoje de olhos abertos sob ameaças que nem sequer conseguimos identificar, tanta a intensidade e a diversidade de manifestações de violência. Entretanto, vale registrar dados recentes da Fundação SEADE ${ }^{17}$ e que pontuam indicadores significativos dessa condição: em 1990 havia na grande São Paulo 450 mil famílias miseráveis. Hoje, 640 mil famílias vivem abaixo da linha da miséria, ou seja: não ganham o suficiente para comprar uma cesta básica por mês, não foram escolarizados e moram em péssimas condições. São 2,3 milhões de pessoas que, excluídas do sistema, dele dependem para sobreviver. Na ausência do Estado, direcionam sua sobrevivência para comportamentos aberrantes na logica do bem-estar, envolvendo a todos, com modalidades de vivência peculiares, no contexto da violência, da aberração, da barbárie, da deterioração da trama social.

. Aqui, frente a esse contexto social e às demandas por saúde por ele produzido e dele decorrente, convivemos com diferentes lógicas assistenciais. Uma voltada aqueles que ainda, e em termos relativos, conseguem financiar seu atendimento, às custas de convênios cada vez mais onerosos. Outra voltada aos excluídos, àqueles que nada mais tem senão a cobertura de um serviço público e seu padrão de ineficiência socialmente induzida. Mediando essas relações, um Sistema Único de Saúde que também convive com uma dupla lógica. A formal, relativa à sua estrutura político-jurídica a configurar um modelo legitimado pela competência e pelo cunho de justiça social. $\mathrm{E}$ a lógica do real e dos obstáculos políticos e corporativos interpostos a sua plena efetivação. Nesse interjogo, o dia a dia daqueles milhões de excluídos que buscam atendimento já vem sendo insistentemente retratado. Assim como as condições em que a prática em saude vem se desenvolvendo. ${ }^{10} \mathrm{Nela}$, carências múltiplas se acumulam, frente a uma demanda cada vez mais crescente. Essa realidade, na sua dimensão quantitativa configura um crescimento do contingente de trabalhadores em saúde polarizado, tendo na presença do médico e do atendente seus extremos de inserção no setor *. Os enfermeiros continuam sendo minoritários em número e também em impacto de

* Palestra proferida por José Paranaguá de Santana, representante da OPAS/OMS, em 20/9/94 no Encontro Universidade e Sistema Único de Saude, Belo Horizonte, 1994. 
ação. Diluídos em diferentes contextos de prática, tentando atender a múltiplas demandas a partir de respostas desvinculadas da propria origem, e, quase sempre, centradas numa lógica a margem da diversidade das culturas e das dinâmicas institucionais, premidos por expectativas de doentes, de familiares, de profissionais de saúdes e, primordialmente, pela esfera de gestão que sempre nos identifica como mantenedores da ordem, vamos reiterando nossa atuação, apesar de tudo e de toda sensação de culpa e de impotência.

Elementos de uma realidade cática, esses dados possuem, ainda, a capacidade de explicitar a fragilidade de concepções sobre Educação e Saude que relativizam o interjogo de poderes, a trama das mediações e dos mecanismos de superação elaborados no decorrer do percurso. Nesse sentido, polarizam o alcance dos próprios poderes, privilegiando a lógica - inclusão - exclusão social. Num extremo, a intervenção reiterativa da exclusão, voltando-se à qualificação dos socialmente pertinentes, realinhando estratégias no sentido do aprimoramento do processo assistencial e educativo. Ainda que atrelada à ordem hegemônica, tais práticas ainda não possuem o poder absoluto de excluir, ainda não elaboraram filtros sociais suficientemente aptos a plena viabilização da exclusão pretendida. Em contrapartida, realocam o poder de resistência daqueles que sobrepujando limites, sobrevivem. No outro extremo dessa elaboração pautada na transcendência de ações, temos a visão das práticas sociais investidas de um poder equalizados de desigualdades configurando a outra face da mesma lógica: na sua essência, o poder da inclusão - exclusão sociais.

Em outro horizonte conceitual, também pautado na supremacia, emerge a intervenção que, tendo como referência o contexto da materialidade das relações sociais de produção, privilegia proposições ao nível das macro relações, desconsiderando projetos centrados em transições na dimensão da internalidade dos processos sociais, inclusive os assistenciais e pedagógicos. Nela, as estratégias teriam a dimensão de bandeiras de luta no enfrentamento das desigualdades, sobrepujando quaisquer outras possibilidades direcionadas no sentido da qualificação dos serviços. Tendo a radicalização da democracia como horizonte, abrir mão de conquistas conjunturais pressupõe pactuar com limites passíveis de superação, inclusive para os excluídos, realinhados na resistência e na possibilidade de macro superações.

Nesse contexto, cabe caracterizar a concepção privilegiada ou seja, o da intervenção que compartilhando o ideário da transformação, investe no aprimoramento de programas de intervenção que se aprimorariam não somente na perspectiva do capital como também, dialeticamente, do trabalho e, por concomitância, dos trabalhadores. Superando a concepção do acesso aos serviços como instrumento equalizador de desigualdades, aqui o investimento decorre da concepção segundo a qual é necessário estar vivo e dominando os códigos de ação para poder e dever lutar. Luta tão mais bem engendrada quanto maior e mais elaborada a bagagem, os instrumentos, a compreensão, e a elaboração de reações 
daqueles que vêm superando os filtros sociais. Obviamente, o modelo como um todo se reelabora, inclusive os sujeitos de mudança. Fiel a princípios fundamentais, reconhecendo na realidade o cenário do interjogo de poderes e de conflitos a serem vivenciados por todos, caberia, nessa perspectiva um investimento concomitante nos programas. Assim, a intervenção no contexto passa a ser efetivamente uma construção social, uma prerrogativa de todos, um cenário, nesse sentido, em aberto, com poder de inclusão - exclusão modulado por ações sociais em constante reelaboração, na dependência da capacidade e da instrumentalização para adequar estratégias de enfrentamento num cenário em mudança.

Nesse contexto, emerge a premência por profissionais aptos, tanto à compreensão dessa supra determinação e dessa conformação político-jurídicaideológica dos aparatos assistencial e educacional como também, da necessidade de uma atuação a despeito da crise, tentando no seu interior, reconsiderar possibilidades e estratégias de qualificação. Essa afirmação não refuta o cunho politico dessas ações. Apenas direciona uma vertente operacional para a lucidez imprescindível à reconstrução.

Finalizando essa etapa de caracterização de referenciais e de pressupostos teóricos cabe, agora, a desafiante configuração do que foi considerado e cunhado, por mim e por CHAVES ${ }^{4,7,8}$, como sendo os princípios constituintes de um novo padrão funcional para a intervenção do enfermeiro em Saude do Adulto Institucionalizado.

Essa iniciativa, ainda que a título de ensaio, deveria, necessariamente, tomar o partido do possível, atenuando a ameaça representada pelo questionamento de um mito central para os enfermeiros: que o cuidado é também mas não somente a prerrogativa da sua existência, institucionalizada para atuar na dinâmica das relações institucionais, incluindo a lógica assistencial; que o cuidar enquanto competência de toda a equipe pressupõe uma esfera de especificidade. Nesse sentido, o cuidar permearia a nossa ação, constituindo o núcleo norteador, o elo de ligação e de ressonância das demais atividades de sua competência e das relações dela decorrentes.

Institucionalmente, essa tem sido a demanda: um enfermeiro apto a responder pelo cuidar dos doentes internados; um profissional instrumentalizado para interagir em equipe, identificando e intervindo adequadamente em situações clínicas específicas; capaz de ter o domínio intelectual da dinâmica assistencial da Unidade.

Reiteradamente convivemos com colegas despreparados para essa atuação polivalente. Frente às múltiplas solicitações, optam por aquelas mais incisivas ou mais próximas dos polos de poder, pulverizando sua atuação, acumulando ações seqüenciadas sob a logica do abafamento de tensões. Colegas manifestando desgaste e culpa pelo não realizado, apesar da transcendência das demandas frente aos instrumentos que dispõem para reconhecer a realidade e adequar estratégias de ação. 
A consciência dessa situação, pautada em vivência pessoal e em aprofundamento analítico, nos levou a investir na conformação do padrão de formação e de atuação centrados na coordenação do processo de cuidar, enquanto conjunto funcional explicitado a partir de agora.

\section{A coordenacão do processo de cuidar: a dimensão da especificidade da atuação do enfermeiro assistencial}

A proposição desse padrão será feita a partir da comparação entre o modelo ainda vigente, denominado padrão I, e o proposto por mim e por CHAVES, padrão II, considerando diferentes categorias analíticas identificadas a partir de agora. ${ }^{4,7,8}$

Iniciando essa etapa, cabe considerar que o projeto de atuação vigente vem efetivando uma concepção articulada de ensino e de prática investida de significados e de representações em transição, ora pautadas em ciência, muitas vezes advindas do senso comum contemporâneo, compondo um processo de ensino com elementos constitutivos peculiares, configurados a seguir. 


\section{Quadro 1 - Feição assumida pelo padrão I de capacitação do enfermeiro para o cuidar.}

\begin{tabular}{|c|c|}
\hline ETAPAS DO PROCESSO & PRESSUPOSTOS \\
\hline 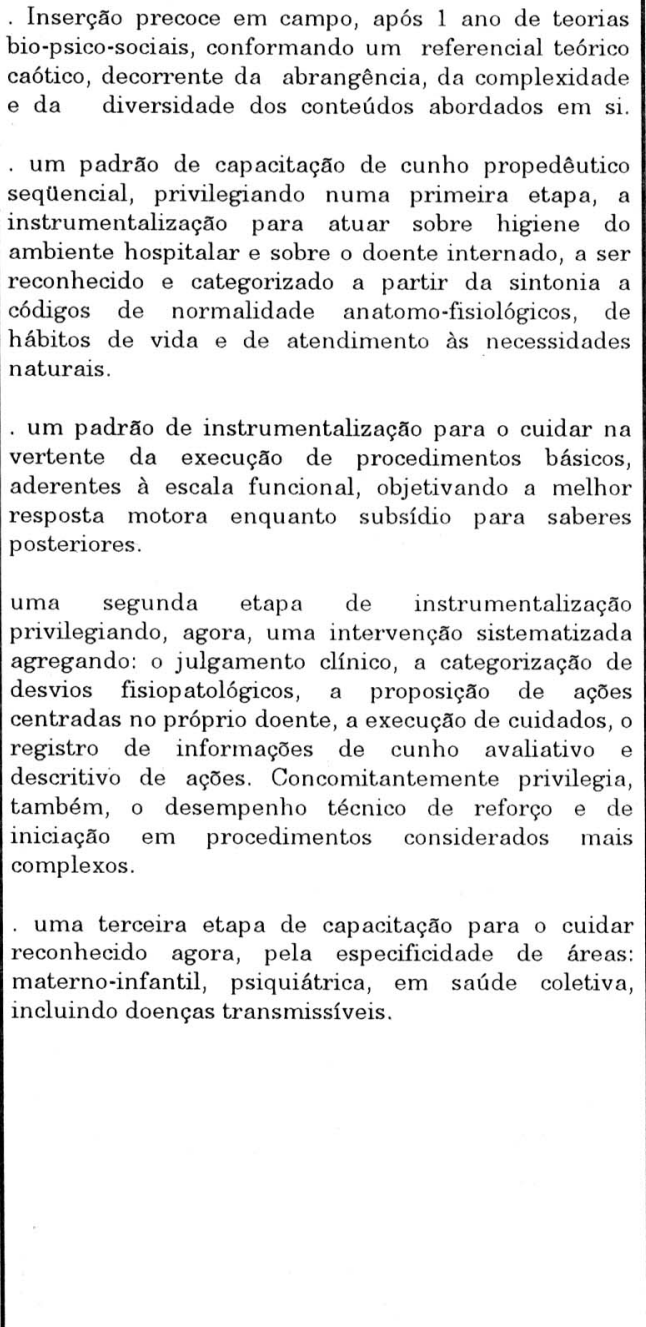 & 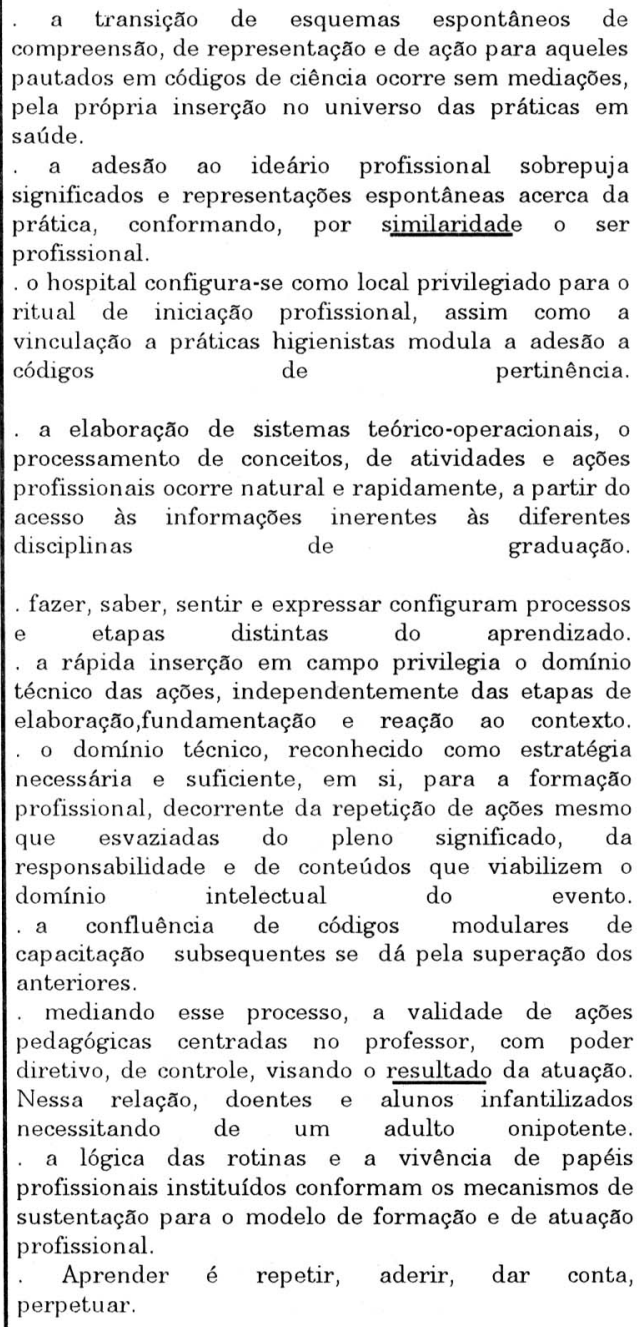 \\
\hline
\end{tabular}

Essa configuração personifica concepções e ações hegemônicas. Efetivamente, diferentes movimentos vêm ocorrendo no interior desse modelo, tentando dar-lhe vitalidade e coerência. Todas assentadas em modificações de 
conteúdos e de estratégias. Entretanto, a partir dessas iniciativas e dos seus limites; forjou-se uma possibilidade de investir na essência desse modelo.

Frente a essa consideração, vale explicitar aspectos desse processo que já trazem em si o registro da própria inadequação, dentre os quais salientamos:

- a sintonia entre demandas discentes apriorísticas e o projeto de formação. Alunos chegam querendo fazer, precisando cuidar. Precocemente, sem condições de desvendar a profissão por eles assumida, sem possibilidades de transitar de uma aproximação caótica com os conteúdos para uma fundamentação ainda que sincrética de referenciais teóricos, sem a vivência de re-conhecer suas próprias representações e significações acerca da Enfermagem, sem recodificarem essa premência pela ação no interior de um processo de formação de nível superior, efetivamente são inseridos no campo, no fazer o cuidado.

. nesse sentido, o hospital passa a configurar-se enquanto elemento imprescindível ao ritual de iniciação discente, ritual requerido e implementado com conivência de ambas as partes. Para o docente, sob a justificativa de que, iniciando a formação pela intervẹnção no ambiente - limpeza e preparo da unidade, diferentes modalidades de arrumação de cama dentre outras técnicas - e na escala funcional de procedimentos - medicação administrada com técnica, porém sem fundamentação farmacológica, sem correlação com tratamento, resultados esperados e obtidos; controle de sinais vitais e dados antropométricos, dissociados das manifestações fisiopatológicas que levaram o doente à internação, dentre outros reducionismos -, estariam dando condições basais para o desenvolvimento futuro. Privilegiando a habilitação motora, estariam viabilizando o posterior domínio intelectual desses eventos. Estariam, ainda, testando o limiar de resistência do aluno em inserir-se em atuações, desse nivel e status, identificando sinais de "inadequação" a serem reelaborados. Para o aluno, a iniciação nesse fazer funcionaria numa dupla lógica: a satisfação de uma compulsão e a relativização de exigências e de preparo intelectual compatível com a formação superior. Podendo fazer desde que sem erros, evitáveis por imitação, postergam o investimento cognitivo na própria formação. Defasagem entre o fazer e o saber de diff́cil justificativa e superação posteriores, na medida em que modificar exigências pressupõe explicitar o vazio do modelo já desenvolvido, configurando polos de tensão na atuação docente.

. um investimento posterior centrado na competência para o julgamento clínico e para uma intervenção sistematizada após a vivência interativa e reiterativa anterior, investida de um poder de 
satisfação suficientemente intenso para dificultar sua reelaboração, ao nível de uma ação, agora, a ser fundamentada, organizada, correlacionada, vivenciada com alto investimento pessoal. Aqui, já se explicita uma etapa de ação pedagógica revestida de violência simbólica, ainda que centrada no cuidar dual.

. o pouco investimento na dimensão das relações profissionais, tangenciada no preparo para a entrevista enquanto técnica voltada a coleta de dados necessários ao reconhecimento e codificação do doente. $O$ pouco investimento na compreensão das condições objetivas nos quais a prática se desenvolve. A ocultação das relações de poder e da adesão aos códigos modulares de pertinência aos papéis sociais desempenhados, inclusive pelos enfermeiros.

. o grande investimento na reiteração do modelo, na adesão periférica à ciência, no abafamento da subjetividade e da especificidade do ser aluno e, conseqüentemente, na possibilidade de potencializar seu capital afetivo - simbólico - cultural, na sua condição de elaborar novos códigos de compreensão e de ação profissional, novos princípios de relacionamento e de interação com a esfera de gestão.

. fundamentalmente, essencialmente, um processo de ensino anacrônico, considerando as perspectivas do sistema formador de nivel superior, idealizado, considerando as demandas por atuação, fragilizado, considerando o pouco investimento no aprimoramento e na potencialização da capacidade discente, porém, ainda válido provavelmente, pela vinculação e satisfação de demandas inconscientes de todos os envolvidos no processo. Satisfação que, ao nivel do consciente convive com desencanto, com sofrimento psíquico. Um processo de ensino que emite duplas mensagens. A valorização de uma prática com estatuto de ciência que compartilha rotinas reiteradas por inércia; o investimento num poder de competência que co-habita o contexto de atuação com ações de domínio leigo; o investimento na imagem e na valorização do aluno, controlando sua iniciativa, moldando sua atuação, adequando sua juventude à uma matriz de pertinência assentada em preconceitos e em contenção de energia; o reconhecimento do poder invasivo e até iatrogênico das práticas em saúde, passiveis de execução com, sem ou apesar do conhecimento; a necessidade de uma atuação sistematizada a partir do doente desde que não se oponha aos horários e prioridades da jornada de trabalho. A valorização da tomada de decisão, da elaboração e proposição desde que não colidam com os esquemas normativos.

. frente à inconsistência e diversidade de mensagens, o papel e a presença constante e cerceadora do professor, mediando ações que 
ele reconhece como transcendentes à capacidade discente. Situações que se desenvolvem com intenso desgaste e sofrimento psíquico na tentativa de viver junto uma experiência existencial única e indivisivel: o tornar-se profissional, o aprender, o evoluir, o tentar, o acertar, o errar enquanto etapas de um projeto maior, de um projeto de vida.

Nesse sentido, reconhecendo a intensidade dessa demanda psíquica e tentando aproximá-la, num novo patamar de ação, compatibilizando-a às demandas sociais e às exigências institucionais, cabe, agora esboçar o padrão proposto, iniciando pela explicitação dos seus pressupostos. Pressupostos que vêm norteando inclusive a reformulação curricular da EEUSP. Princípios de um ideário conformado no decorrer de nossa vivência na Comissão de Graduação, coordenando o processo de reformulação, bem como na trajetória acadêmica na qual investimos, tendo o processo de ensino de nível superior como questão teórica central.

\section{Pressupostos teóricos que vem norteando a proposição do padrão II de capacitação do enfermeiro.}

. a formação de nível superior ${ }^{5}$, enquanto etapa de desenvolvimento profissional do adulto, constitui um processo através do qual o aluno penetra na vida intelectual e no contexto social peculiar à sua área de atuação. Essa concepção deve subsidiar superações reducionistas da capacidade discente, que identificam o aluno ora como um ser infantil, ora como um adulto com limitaçōes tidas como insuperáveis. Nesse sentido, um bom aprendizado deverá ser capaz de identificar e utilizar, tanto os ciclos de desenvolvimento cognitivo já completados, como também aqueles em maturação, resultantes da dependência do aluno em desempenhar determinadas atuaçōes. ${ }^{19}$

- identificar o aluno como adulto pressupõe estabelecer uma relação pedagógica com uma pessoa apta a dominar processos psicológicos superiores - pensamento, linguagem e comportamento volitivo. ${ }^{18} \mathrm{Um}$ adulto apto a aprimorar capacidades especializadas para pensar sobre várias coisas.

. Esse aprimoramento cognitivo - simbólico - afetivo é primordialmente o desenvolvimento de um conjunto de atividades específicas, que se complementarão na medida em que houver elementos comuns entre elas. Elementos elencados a partir de esquemas lógicos a serem sistematicamente explicitados. Pautado nesse argumento, superamos o caráter propedêutico de áreas do cuidar sobre outras. Por isso, também, a confluência de conteúdos 
complementares às áreas temáticas desde o primeiro ano de graduação, viabilizando o acesso aos códigos de conduta profissional bem como aos instrumentos de pesquisa em concomitância com o domínio gradativo de habilidades específicas. A lógica do encadeamento dos conteúdos deve se pautar, portanto, no carater complementar das disciplinas na medida em que todas incluem, igualmente, processos de dedução, compreensão, evolução de noç̃es, interpretação de casualidade, culminando no domínio de práticas e de códigos de atuação peculiares.

. à graduação caberia subsidiar uma etapa peculiar desse desenvolvimento, levando o aluno à resolução, de forma independente, de problemas cada vez mais avançados. Essa é a compreensão que temos de complexidade, independente da área, de conteúdos e de açoes. Nesse sentido. o bom aprendizado será aquele que conseguir se adiantar aos ciclos de desenvolvimento já completados por esse aluno. Será aquele apto a agilizar o nível potencial de desenvolvimento desse aluno, determinado pela dependência de atuações ${ }^{28,19}$. Essa seria a categoria a definir estratégias específicas para alunos específicos, culminando, ao final do $4^{\circ}$ ano, porém, por caminhos peculiares, num patamar basal para todos.

- o desenvolvimento rumo a essa autonomia responsável, fundamentada e compativel com o nível de graduação pressupõe a superação gradativa de esquemas concretos, a superação da adesão $a$ códigos de prioridades externas e estranhas ao momento e à necessidade de aprendizado. Em decorrência, essa seria a possibilidade do professor efetivamente consolidar o seu espaço no contexto assistencial. Espaço além da lógica das rotinas institucionais e da sujeição a relações de poder estranhas ao seu contexto. Emancipação decorrente da sua identidade acadêmica, ou seja, da intervenção organizada a partir da questão teórica central que configura e norteia o seu universo de investigacão no âmbito do cuidar. Aqui, também, o espacso do aluno desenvolver sua atividade consciente, característica primordial do desenvolvimento cognitivo do adulto. Aqui, a oportunidade do aluno internalizar experiências vivenciadas em conjunto, assumidas por vontade, gerando um aprendizado pautado na experimentação e não na repetição esvaziada de sentido e de significados. Esse aprendizado seria produto da internalização do vivenciado, da sua reinterpretação, transformando a experiência num processo intrapessoal, capaz de gerar novos sistemas e novas leis de atuacão. ${ }^{18}$ Aqui, portanto, a identidade complementar do ser aluno e do ser docente de graduacão em Enfermagem. ${ }^{5}$ 


\section{Pressupostos operacionais que vem norteando a proposição do padrão II de capacitação do enfermeiro.}

. o reconhecimento ${ }^{8}$ da articulação entre os mundos da prática assistencial e docente aqui reconhecidas como entidades específicas, com papéis e funç̃es peculiares, ambas consideradas como elementos e produtos da dinâmica de atuação acadêmica e assistencial;

- a necessidade de validação de novos projetos de intervenção profissional na medida em que a tecnologia passa a exigir integração multi-profissional, flexibilidade de relações, versatilidade nas intervenções, nos padrões, nos instrumentos e nos ritmos das atividades;

. um padrão de organização curricular flexível, dinâmico, centrado na relaç̃o professor - aluno, balizado por linhas de atuação de interesse comum a ambos e ao grupo como um todo, valorizando a interdisciplinaridade reconhecida como necessária à consolidação de novos modelos teórico-práticos;

. um planejamento de tempo e de estratégias que potencializem o desenvolvimento discente e docente em consonância com as exigências da Universidade;

. a organização dos conteúdos disciplinares em grandes áreas temáticas, viabilizando a opção e a complèmentaridade de conteúdos; - a busca de um padrão de competência pautado na autonomia para a construção do domínio intelectual dos eventos privilegiados por docentes e alunos;

. a superação de reducionismos, ou seja, de projetos de intervenção num "corpo dissociado tanto da sua dimensão intropsíquica quanto do seu contexto social"s

\section{A dimensão das concepções que fundamentam a proposição do padrão II de capacitação do enfermeiro assistencial}

\section{Categoria demanda por cuidar}

. manifestações comportamentais e de condições físicas decorrentes de alterações bio-psico-sociais desencadeadas pelo processo de ser doente e estar internado, passiveis de atendimento mediante $o$ desempenho de ações da equipe de enfermagem que conceitualmente contemplam as três dimensões, com poder de operacionalização predominantemente centrado na dimensão do biológico. 


\section{Categoria prática do enfermeiro}

. Intervenção que considera o contexto social e institucional enquanto balizas para o realinhamento de práticas, com poder compartilhado intra e inter equipe constituintes do processo de produção em saúde, com intervenções junto a uma pessoa e junto a uma dinâmica institucional. Nela a lógica de atuação se organiza a partir de condiçoes objetivas, considerando as demandas por cuidar do conjunto dos doentes e as possibilidades objetivas de atendê-los.

\section{Categoria Processo de Ensino}

Conceitualmente fundamentado na esfera do biologico, do psicossocial, do simbólico, do educacional e do político - enquanto relações de poder interpessoais, intra e inter - institucionais.

- Operacionalmente organizado na instrumentalização sobre 0 processo de trabalho em saúde e para a coordenação do processo de cuidar em Enfermagem.

Nesse modelo em validação, conceituamos processo de cuidar enquanto: seqüência dinâmica e articulada de ações necessárias e suficientes para a construção, desempenho e validação do trabalho de equipe de enfermagem. agregando intervenç̃es especificas (cuidar), ações complementares $e$ interdependentes do conjunto multiprofissional (assistir-cuidar) desenvolvidas em contextos peculiares. ${ }^{.}$Nessa dinâmica de trabalho em saúde, o enfermeiro assistencial tem por competência a coordenação do processo de cuidar e como instrumentos: a sistematização do cuidar, a mediação das relações profissionais e a representação da sua equipe ao nível das esferas de gestão, interface com o processo de trabalho administrar. ${ }^{4}$

Vale salientar que esses pressupostos reconhecidamente convivem com limites que, sendo peculiares ao grupo, não deixaram de refletir vazios conceituais e operacionais genéricos na medida em que acessar, fundamentar e implementar códigos de compreensão e de ação revestidos do poder da competência, síntese da confluência bio-psico-social configura um desafio da humanidade. Desafio ainda maior quando esse interjogo se desenvolve no contexto de vida de um adulto agora reconhecido como demandante de práticas e de intervenções de Saúde a caracterizar reelaborações de significados, de representações e de necessidades decorrentes dessa situação. No momento, essas seriam balizas a conformar um. grande e necessário desafio para a validação desse modelo. ${ }^{6}$

Numa tentativa de síntese, vale expressar uma representação desse ideário. 
Quadro 2 - Categorias analíticas constituintes dos padrões de formação do enfermeiro assistencial.

\begin{tabular}{|c|c|c|}
\hline CATEGORIAS & $\left.\right|_{\text {- CUIDADO }} ^{\text {I }}$ & 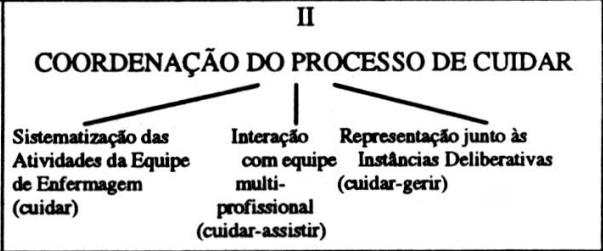 \\
\hline $\begin{array}{l}\text { CONTEÚDOS } \\
\text { HEGEMÔNICOS }\end{array}$ & $\begin{array}{l}\text { CIÊNCIAS BIOLÓGICAS } \\
\text { ENFERMAGEM }\end{array}$ & $\begin{array}{l}\text { CIÊNCIAS BIOLÓGICAS, EDUCACIONAIS, } \\
\text { COMPORTAMENTAIS, SOCIAIS } \\
\text { (PSICOLOGIA SOCIAL), ENFERMAGEM }\end{array}$ \\
\hline NÚCLEO DA AÇÃO & CORPO & $\begin{array}{l}\text { PESSOAS - PROFISSIONAIS, USUÁRIOS, } \\
\text { FAMILIARES, - E O CONTEXTO DA PRÁTICA }\end{array}$ \\
\hline OBJETO DE PRÁTICA & CUIDAR DO CORPO & $\begin{array}{l}\text { COORDENAÇÃO DO PROCESSO DE CUIDAR } \\
\text { DA PESSOA USUÁRIA }\end{array}$ \\
\hline ABRANGÊNCIA & RELAÇÃO DUAL & $\begin{array}{c}\text { RELAÇÕES - INTERPESSOAIS } \\
\text { - INSTITUCIONAIS } \\
\text {. interface cuidar-assistir } \\
\text {. interface - cuidar - gerir }\end{array}$ \\
\hline
\end{tabular}

Aqui se explicita o alcance da ação pretendida, o efetivo reconhecimento de uma atuação para além do cuidado direto enquanto cuidado específico do enfermeiro, o re-conhecimento do contexto das relações profissionais e institucionais como efetivo campo de atuação. Aqui a premência pela abordagem teórica confluente, consolidando núcleos de fundamentação enquanto substrato de um padrão de atuação na dinâmica do cuidar. Nesse padrão, uma possibilidade de repactuar códigos de relacionamento profissional e institucional em decorrência de uma efetiva e abrangente instrumentalização. Enfim, aqui uma possibilidade de, dentro do sistema, atrelada a demandas apriorísticas, propor um movimento no sentido da qualificacão possível.

Esse novo padrão de profissionalização representaria um avanço na medida em que ":

. propõe uma sincronia entre uma demanda subjetiva por cuidar. uma demanda lambém subjetiva por ser cuidado, de uma demanda institucional em ter alguém que responda pelo cuidar, de uma demanda social em manter a vida, controlando a todos;

. possibilita um reencontro do enfermeiro com sua própria identidade, pautando-se numa relação mais segura e menos conflitante consigo mesmo e com a sua profissĩo; 
. sugere os principios constitutivos de uma prática que considera o real e que poderá contribuir para a consolidação da Enfermagem com estatuto de ciência que compartilha da esfera do curar a partir da sua especificidade circunstancial: a coordenaçấo do processo de cuidar;

- responde a uma urgência histórica: a reestruturaçẩo das instituiç̃es e práticas de saúde, a partir da proposição de alternativas aos padrões de intervenção e de relacionamento profissionais usuais.

A proposição do deslocamento do nosso objeto de prática e da ampliação na esfera do nosso trabalho pressupõe uma ruptura com o vigente e com o desvio de funções. Poderemos ou não levá-la em consideração. Entretanto, devemos entendêla como uma tentativa de precisar e de evidenciar tanto o problema que está em cena, como as perspectivas para a sua superação. Na medida em que jogos da vontade não são feitos por pessoas ingênuas, do nosso querer e poder dependerá a crítica, o aprimoramento, a experimentação desta a proposta. No cenário determinado e determinante das práticas de saúde, identificamos o desafio bem como o espaço da nossa intencionalidade enquanto possibilidade de revolver conceitos, princípios e valores, avançando, ou não, na consolidação da Enfermagem. ${ }^{4}$

IDE, C.A.C. The re-identification of the referentials to the nursing interventions in the adult health care. Rev.Esc.Enf.USP, Special Issue, p.9-32, dec. 1996.

The focus of this study is on proposition of a new professional formation. In this context, the modulating codes of pedagogical action were set up, emphasizing the analysis of the consistency of the reference systems that give them support.

UNITERMS: Teaching -apprenticeship process. Care process.

\section{REFERÊNCIAS BIBLIOGRÁFICAS}

1. ASSOCIAÇĀO BRASILEIRA DE ENFERMAGEM. Subsídios para a conceituacão da assistencia rumo d̀ reforma sanitária. Braślia, 1987.

2. BORSOI, I.C.F. Saúde mental e trabalho: um estudo de caso da enfermagem. Săo Paulo, 1992. 97p. Dissertaça (Mestrado). Instituto de Psicologia, Pontifícia Universidade Católica.

3. HELLER, A. O cotidiano e a história. São Paulo, Paz e Terra, 1992.

4. IDE, C.A.C. A coordenaçáo do processo de cuidar: caminho para a prática, perspectiva para a profissto. In: ENCONTRO INTERNACIONAL'PESQUISA EM ENFERMAGEM: UMA QUESTÃo DE SAÚDE'. São Paulo, 1992. Programa. São Paulo, Escola de Enfermagem da USP, 1992. p.61. 
5. Graduaçăo em enfermagem: a configuração do novo currículo da EEUSP/ Apresentado ao Seminário Nacional de Diretrizes para a Educação em Enfermagem, Rio de Janeiro, 1994/

6. A formaçáo em saúde do adulto: caracterizaçăo do programa de pós-graduaçăo em enfermagem. In: SEMINÁRIO NACIONAL EM SAÚDE DO ADULTO: A FORMAÇĀO EM DEBATE, 1. Curitiba, 1995. Programas. Curitiba, Departamento de Enfermagem da Universidade Federal do Paraná, 1995. p. 27.

7. IDE, C.A.C.; CHAVES, E.C. Fundamentos para a construçáo de uma teoria de ensino/ Apresentado no curso de atualizaça " $O$ ensino do processo de cuidar do adulto: perspectivas para a questio". São Paulo, 1992/

8. Educação em enfermagem: o movimento constituinte da sua identidade/Apresentado no Seminário Nacional de Diretrizes para a Educaçao em Enfermagem, Rio de Janeiro, 1994 al

9. A singularidade dos sujeitos na vivência dos papéis sociais envolvidos na hospitalização/Apresentado na Jornada Wanda de Aguiar Horta. Sáo Paulo, 1994 b)

10.MÁ administração ó responsável por falta de dinheiro para saúde pública. Folba de Săo Paulo. Săo Paulo, 6 ago. 1995 p. 1-12.

11. MARTINS, R.C.T. A interaçăo processo de trabalho - cultura institucional: a prática docente na enfermagem como categoria avaliativa. São Paulo, 1994. 140p. Dissertação (Mestrado) - Escola de Enfermagem, Universidade de Sxo Paulo.

12. MASETTO, M.T. Em sala de aula de $3^{2}$ grau ainda se aprende... São Paulo, 1991. 127p. Tese (Livre Docencia) Faculdade de Educaça, Universidade de Sáo Paulo.

13. MENZIES, I. O funcionamento das organizacoes como sistemas sociais de defesa contra a ansiedade. São Paulo, Escola de Administração de Empresas de São Paulo, Fundação Getúlio Vargas. 1970/Mimeografado/

14. O Pensador do Naufrágio. Folha de Săo Paulo, Săo Paulo, 23 abr. 1995. cad. 5, p. 4.

15. RIBEIRO, M.R.R. Vivencia da (in) certeza: a prática ritualística de professores de enfermagem pediátrica. Săo Paulo, 1995. 248p. Dissertação (Mestrado) Escola de Enfermagem, Universidade de São Paulo.

16. RODRIGUES, A.M. Operário operária: estudo exploratório sobre o operariado industrial da grande São Paulo. São Paulo, Símbolo, 1978.

17. Vivem em probreza absoluta 2,3 milhres na Grande São Paulo. Folha de São Paulo, 20 abr. 1995. cad. 3, p. 2.

18. VYGOTSKY, L.S. Pensamento e linguagem. São Paulo, Martins Fontes, 1991a

19. VYGOTSKY, L.S. A formaç̃o social da mente: o desenvolvimento dos processos psicológicos superiores. Sáo Paulo, Martins Fontes, 1991 b 